\title{
A single parameter representation of hygroscopic growth and cloud condensation nucleus activity - Part 3: Including surfactant partitioning
}

\author{
M. D. Petters ${ }^{1}$ and S. M. Kreidenweis ${ }^{2}$ \\ ${ }^{1}$ Department of Marine Earth and Atmospheric Sciences, North Carolina State University, Raleigh, NC, USA \\ ${ }^{2}$ Department of Atmospheric Science, Colorado State University, Fort Collins, CO, USA \\ Correspondence to: M. D. Petters (mdpetter@ncsu.edu)
}

Received: 17 August 2012 - Published in Atmos. Chem. Phys. Discuss.: 3 September 2012

Revised: 15 January 2013 - Accepted: 16 January 2013 - Published: 28 January 2013

\begin{abstract}
Atmospheric particles can serve as cloud condensation nuclei in the atmosphere. The presence of surface active compounds in the particle may affect the critical supersaturation that is required to activate a particle. Modelling surfactants in the context of Köhler theory, however, is difficult because surfactant enrichment at the surface implies that a stable radial concentration gradient must exist in the droplet. In this study, we introduce a hybrid model that accounts for partitioning between the bulk and surface phases in the context of single parameter representations of cloud condensation nucleus activity. The presented formulation incorporates analytical approximations of surfactant partitioning to yield a set of equations that maintain the conceptual and mathematical simplicity of the single parameter framework. The resulting set of equations allows users of the single parameter model to account for surfactant partitioning by applying minor modifications to already existing code.
\end{abstract}

\section{Introduction}

Köhler theory predicts the supersaturation that is required to activate a particle into a cloud droplet. Fundamentally, this supersaturation depends on the number of moles of solute in solution and the surface tension of the aqueous solution/air interface. Simple textbook versions (e.g. Seinfeld and Pandis, 2006) of Köhler theory model the particle as composed of a single compound that is non-volatile and infinitely soluble in water. Moles in solution are computed from the molar volume of the compound and the activity of water is modelled using modified versions of Raoult's law that account for nonideal solution behaviour. Because typical atmospheric particles are composed of a multitude of different compounds with different and often unknown molar volumes and solubilities, simple single parameter expressions have been developed to account for the effects of solutes on drop growth and activation (e.g. Svenningsson et al., 1994; Rissler et al., 2006; Petters and Kreidenweis, 2007; Wex et al., 2007; Petters and Kreidenweis, 2008; Rissler et al., 2010). In this framework the effective cloud condensation nuclei (CCN) activity is described by a hygroscopicity parameter, hereafter denoted $\kappa$, that can be directly observed even if the particle composition is unknown.

The approximate relationship between the dry particle diameter $\left(D_{\mathrm{d}}\right)$, the critical saturation ratio $\left(S_{\mathrm{c}}\right)$, and $\kappa$ is given by (Petters and Kreidenweis, 2007)

$\kappa=\frac{4 A^{3} \sigma_{\mathrm{s} / \mathrm{a}}^{3}(T)}{27 T^{3} D_{\mathrm{d}}^{3} \ln ^{2} S_{\mathrm{c}}}$,

where $A=8.69251 \times 10^{-6} \mathrm{~K} \mathrm{~m}^{3} \mathrm{~J}^{-1}, \quad \sigma_{\mathrm{s} / \mathrm{a}}(T) \quad$ is the temperature-dependent surface tension of the solution/air interface, and $T$ is temperature. The so-found $\kappa$ has been referred to as $\kappa_{\mathrm{CCN}}, \kappa_{\text {effective }}$, or $\kappa_{\text {apparent }}\left(\kappa_{\text {app }}\right)$ to specify that the value has been derived from $\mathrm{CCN}$ measurements and/or that a constant temperature-dependent surface tension was assumed in the calculation of $\kappa$ from an $S_{\mathrm{c}}, D_{\mathrm{d}}$ pair (Pöschl et al., 2009; Sullivan et al., 2009a; Christensen and Petters, 2012). The semi-empirical characterization of CCN activity in terms of $\kappa_{\text {app }}$ if a self-consistent set of surface tension and temperature is applied when computing 
$S_{\mathrm{c}}$ values from experimentally determined $\kappa_{\text {app }}$. This holds true even if the assumed value for $\sigma_{\mathrm{s} / \mathrm{a}}(T)$ is incorrect. In this case $\kappa_{\text {app }}$ is simply a parameterization that implicitly accounts for surface tension effects. Equation (1) is valid for $\kappa>0.2$ (Petters and Kreidenweis, 2007), but may be used for $\kappa>\sim 0.01$ if small numerical errors are acceptable. One utility of $\kappa_{\text {app }}$ is that changes in $\kappa_{\text {app }}$ can be related to changes in chemical composition via chemical reactions (Petters et al., 2006; George and Abbatt, 2009; Jimenez et al., 2009; Sullivan et al., 2009b) or mixing with other compounds (e.g. Gunthe et al., 2009; Dusek et al., 2010) and thus it can be used as vehicle to parameterize the effect of these processes on CCN activation in models (Lohmann and Hoose, 2009).

Equation (1) can be derived from a model that describes the effect of the solute on the water activity of the solution (Petters and Kreidenweis, 2007)

$$
\frac{1}{a_{\mathrm{w}}}=1+\kappa \frac{V_{\mathrm{s}}}{V_{\mathrm{w}}}
$$

where $a_{\mathrm{w}}$ is the water activity, and $V_{\mathrm{s}}$ and $V_{\mathrm{w}}$ are the volumes of solute and water, respectively. The definition of $\kappa$ used in Eq. (2) is independent of surface tension and if Eq. (2) were used to represent non-ideal solutions, $\kappa$ would become a function of the solute concentration. For aerosols of unknown composition, this variable $\kappa$ can be determined from hygroscopic growth measurements made by a humidified tandem differential mobility analyser (HTDMA) or an electrodynamic balance (Kreidenweis et al., 2005). It can also be determined from models or theories that predict the water activity as a function of chemical composition. Kappa values determined by such techniques describe the intrinsic ability of the particles' chemical composition to promote water uptake. To distinguish these values from the $\mathrm{CCN}$ derived techniques, these $\kappa$ 's have been referred to as $\kappa_{\text {Raoult }}, \kappa_{\text {intrinsic }}$, $\kappa_{\text {chem }}, \kappa_{\mathrm{AIM}}$, or $\kappa_{\mathrm{GF}}$ where the subscript denotes the origin of the data or model used in conjunction with Eq. (2) (Raoult $=$ Raoult's law, AIM = Aerosol Inorganic Model, chem $=$ chemical composition, GF = hygroscopic diameter growth factor data). For example, AIM (Clegg et al., 1998) models $a_{\mathrm{w}}$ as a function of the mole fraction of water in electrolyte solutions, from which $\kappa$ can be inferred. Here we adopt the broad terms $\kappa_{\text {app }}$ and $\kappa_{\text {chem }}$ to distinguish if it was derived via Eqs. (1) or (2), respectively.

One question that has received attention in the literature is the degree of agreement between $\kappa_{\text {chem }}$ and $\kappa_{\text {app }}$. For many systems, including pure compounds (Petters and Kreidenweis, 2007; Chan et al., 2008; Wex et al., 2010), complex organic mixtures (Carrico et al., 2008; Duplissy et al., 2008; Petters et al., 2009c; Wex et al., 2007), and ambient aerosol (Vestin et al., 2007; Mochida et al., 2010, 2011), the agreement is within $10-30 \%$. Other studies, however, have either implicitly or explicitly reported significant discrepancies between $\kappa_{\text {chem }}$ and $\kappa_{\text {app }}$ (e.g. Moore et al., 2008; Engelhart et al., 2008; King et al., 2009; Wex et al., 2009;
Good et al., 2010a; Irwin et al., 2010; Padro et al., 2010). This discrepancy has been attributed to a combination of several effects, including gradual dissolution of sparingly soluble compounds at high relative humidity (Petters and Kreidenweis, 2008; Petters et al., 2009b), highly non-ideal solution behaviour (Prenni et al., 2007; Petters et al., 2009b), measurement uncertainties related to HTDMA operation including residence time and other unresolved sources of disagreements between instruments of similar design (Sjogren et al., 2007; Good et al., 2010b), and unaccounted surface tension effects when applying Eq. (1) to derive $\kappa_{\text {app }}$ (Moore et al., 2008; Engelhart et al., 2008; King et al., 2009; Wex et al., 2009; Good et al., 2010a; Irwin et al., 2010; Padro et al., 2010).

It has long been known that surface active compounds are present in the atmospheric aerosol (Seidl and Hänel, 1983; Shulman et al., 1996; Facchini et al., 1999, 2000). Based on Eq. (1, the relative influence on critical supersaturation of variations in $\sigma_{\mathrm{s} / \mathrm{a}}$ and $\kappa$ is $\mathrm{d} \ln \kappa=-3 \mathrm{~d} \ln \sigma_{\mathrm{s} / \mathrm{a}}$ meaning that a $10 \%$ decrease in $\sigma_{\mathrm{s} / \mathrm{a}}$ has the same effect than does a $30 \%$ increase in $\kappa$ (Kreidenweis et al., 2009). Thus even small reductions in surface tension are predicted to significantly reduce the critical supersaturation. However, the exact value of $\sigma_{\mathrm{s} / \mathrm{a}}$ entering Eq. (1) is not straightforward to calculate. Surface active compounds are preferentially located at the solution/air interface resulting in a radial concentration gradient of the surfactant in the droplet. As the surfactant migrates to the interface, the bulk of the droplet becomes depleted and the surfactant concentration decreases. Because the amount of surfactant in each particle is finite, and the surface-tovolume ratio is large in small droplets, there are cases where not enough surfactant molecules are available to populate the surface even if all molecules would be allowed to partition to the interface. The effect causes smaller particles to not fully express the surface tension reduction that would be expected from the concentration of surfactant that is present in the droplet solution (Bianco and Marmur, 1992; Li et al., 1998). Surfactants are generally organic compounds that have large molar volumes and thus low $\kappa_{\text {chem }}$ (Petters et al., 2009a). In mixed particles that are composed of surfactant and inorganic salts, the overall $\kappa_{\text {chem }}$ can be modelled as the volume weighted average of the constituents' $\kappa$-values (Petters and Kreidenweis, 2007). As the volume fraction of surfactant in the dry particle increases, the net $\kappa$ of the particle decreases together with surface tension, resulting in a larger critical supersaturation when comparing the mixed particle to a pure inorganic particle of the same dry diameter (Rood and Williams, 2001). The decrease of the bulk phase solute concentration increases the water activity of the droplet and can partially or fully compensate for the surface tension reduction occurring at the droplet air interface (Sorjamaa et al., 2004; Prisle et al., 2008, 2010; Ruehl et al., 2010). These effects must be accounted for when altering the value $\sigma_{\mathrm{s} / \mathrm{a}}$ that enters into Eq. (1). 
The objective of this paper is to introduce within the $\kappa$ framework a hybrid model that accounts for surface tension lowering. The model can be used with surface tension data from bulk measurements while maintaining a thermodynamically rigorous description of the surface-to-bulk partitioning process. The developed framework is consistent with, and builds upon similar simplified treatments of the problem that were recently reported in the literature (Topping, 2010; Prisle et al., 2011; Raatikainen and Laaksonen, 2011). The resulting conceptual framework is useful for highlighting several uncertainties that hinder our ability to precisely pinpoint the role of surface tension in cloud droplet activation using current measurement and data analysis approaches.

\section{Model}

\subsection{Basic equations}

In Gibbs surface thermodynamics the system is modeled as consisting of three phases, the gas phase, the surface phase and the bulk phase. To denote composition variables of the different compounds present in the various phases we adopt the following notation: $F_{y, i}^{x}$ where $F$ denotes the composition variable ( $n=$ moles, $c=$ concentration, $V=$ volume), $x$ denotes the phase ( $b=$ bulk, $s=$ surface, $t=$ total or bulk + surface), $y$ denotes the component ( $s=$ solute, $w=$ water), and the index $i$ denotes the $i$-th component in the mixture. For examples, $V_{\mathrm{s}, i=\mathrm{sft}}^{\mathrm{b}}$ denotes the volume of the surfactant in the bulk phase and $n_{\mathrm{w}}^{\mathrm{t}}$ denotes the total number of moles of water in the droplet. If the index $i$ is omitted, the sum of all components is implied; e.g. $V_{\mathrm{s}}^{\mathrm{b}}$ and $V_{\mathrm{s}}^{\mathrm{t}}$ denote the volume of all solutes in the bulk phase or the particle, respectively. A list of symbols and their definition is provided in the Appendix.

The saturation ratio, $S$, over an aqueous solution droplet can be calculated from

$S=a_{\mathrm{w}} \exp \left(\frac{4 \sigma_{\mathrm{s} / \mathrm{a}} M_{\mathrm{w}}}{R T \rho_{\mathrm{w}} D}\right)$,

where $\rho_{\mathrm{w}}$ is the density of water, $M_{\mathrm{w}}$ is the molecular weight of water, $R$ is the universal gas constant, and $D$ is the diameter of the droplet. For a system consisting of multiple solutes, Eq. (2) can be expressed as (Petters and Kreidenweis, 2007)

$$
\frac{1}{a_{\mathrm{w}}}=1+\sum \kappa_{i} \varepsilon_{i} \frac{V_{\mathrm{s}}^{\mathrm{b}}}{V_{\mathrm{w}}}
$$

where $\varepsilon_{i}$ is volume fraction of the of the $i$-th component in the particle. Because compounds that are located in the surface layer do not contribute to the water activity (Sorjamaa et al., 2004), the volume of solute in the bulk phase $\left(V_{\mathrm{s}}^{\mathrm{b}}\right)$ enters in Eq. (4). For compounds that do not partition between the surface and the bulk, the amount of solute in the surface phase is zero $\left(V_{\mathrm{s}, i}^{\mathrm{s}}=0\right)$ and there is no distinction between bulk and total volumes $\left(V_{\mathrm{s}}^{\mathrm{b}}=V_{\mathrm{s}}^{\mathrm{t}}=\pi D_{\mathrm{d}}^{3} / 6\right)$. If, in contrast, the compound partitions to the surface, the number of moles/volume of solute in solution is reduced as described by Gibbs adsorption theory. Generally the relevant equations must be solved numerically to find the concentration gradient of each compound or ion in solution (Sorjamaa et al., 2004). For the special case where only the surfactant partitions and a number of additional assumptions are introduced an analytical solution exists (Eq. 11 in Raatikainen and Laaksonen, 2011)

$$
\begin{aligned}
& V_{\mathrm{s}, i=\mathrm{sft}}^{\mathrm{b}}=\frac{\alpha_{\mathrm{stt}}\left(g+\sqrt{g^{2}+4 \varepsilon_{\mathrm{sft}} V_{\mathrm{s}}^{\mathrm{t}} \beta V / \alpha_{\mathrm{sft}}}\right)}{2} \\
& g=\frac{\varepsilon_{\mathrm{sft}} V_{\mathrm{s}}^{\mathrm{t}}}{\alpha_{\mathrm{stt}}}-\beta V-\frac{A \Gamma_{\max }}{v}
\end{aligned} .
$$

In Eq. (5), $V$ is the volume of the solution which is equal to the droplet volume $\left(\pi D^{3} / 6\right)$ if no undissolved compounds are present, $A=\pi D^{2}$ is the droplet surface area, $\Gamma_{\max }$ is the maximum surface excess, $\beta$ is the inverse activity coefficient, $\alpha_{\mathrm{sft}}$ is the molar volume of the surfactant, and $v$ is the total number of cations $\left(v_{+}\right)$and anions $\left(v_{-}\right)$resulting from the surfactants' dissociation. In the formulation of Eq. (5) we adopted the molarity scale (moles per volume of solution) since $\beta$ is often reported in these units. The mole quantities appearing in the original formulation by Raatikainen and Laaksonen were converted to volumes $\left(n_{\mathrm{s}, i=\mathrm{sft}}^{\mathrm{b}}=V_{\mathrm{s}, i=\mathrm{sft}}^{\mathrm{b}} / \alpha_{\mathrm{sft}}\right.$ and $n_{\mathrm{s}, i=\mathrm{sft}}^{\mathrm{t}}=V_{\mathrm{s}, i=\mathrm{sft}}^{\mathrm{t}} / \alpha_{\mathrm{sft}}=$ $\left.\varepsilon_{\mathrm{sft}} V_{\mathrm{s}}^{\mathrm{t}} / \alpha_{\mathrm{sft}}\right)$ to aid the introduction into the final $\kappa$-equations.

Using the result from Eq. (5), the surface tension can be computed from the semi-empirical Szyskowski equation

$\sigma_{\mathrm{s} / \mathrm{a}}=\sigma_{0}-R T \Gamma_{\max } \ln \left(1+\frac{V_{\mathrm{s}, i=\mathrm{sft}}^{\mathrm{b}}}{\alpha_{\mathrm{sft}} \beta V}\right)$,

where $\sigma_{0}$ is the surface tension at zero solute concentration. Equation (6) is valid as long as $c<c_{\mathrm{cmc}}$ where CMC denotes the critical micelle concentration. Note that we have replaced the molar concentration that is usually used in Eq. (6) with the already defined quantities: $c_{\mathrm{s}, i=\mathrm{sft}}^{\mathrm{b}}=\frac{V_{\mathrm{s}, i=\mathrm{stt}}^{\mathrm{b}}}{\alpha_{\mathrm{sft}} V}$.

It is useful to further define the ratio $\xi_{i}=V_{\mathrm{s}, i}^{\mathrm{b}} / V_{\mathrm{s}, i}^{\mathrm{t}}$ which expresses the fraction of solute of the $i$-th component that is present in the bulk relative to the total. For compounds that do not partition between the bulk and surface $\xi_{i}=1$, while $1>\xi_{i}>0$ holds for compounds that are present in both phases. Using this definition Eq. (2) can be written in terms of $V_{\mathrm{s}}^{\mathrm{t}}$ since by definition the bulk concentration can be computed from the volume fraction in the mixture, the partitioning ratio, and the total volume of solute in the droplet $\left(V_{\mathrm{s}, i=\mathrm{sft}}^{\mathrm{b}}=\varepsilon_{\mathrm{sft}} \xi_{\mathrm{sft}} V_{\mathrm{s}}^{\mathrm{t}}\right)$. Following the steps that are identical to those in Petters and Kreidenweis (2007), i.e. expressing the volumes in Eq. (4) in terms of the wet and dry diameters, solving for $a_{\mathrm{w}}$ and combining the result with Eq. (3) yields the $\kappa$-Köhler equation that is valid for surface active species: 
$S(D)=\frac{D^{3}-D_{\mathrm{d}}^{3}}{D^{3}-D_{\mathrm{d}}^{3}(1-\kappa)} \exp \left(\frac{A \sigma_{\mathrm{s} / \mathrm{a}}}{T D}\right)$

$\kappa=\sum \varepsilon_{i} \xi_{i} \kappa_{i}$

$\sigma_{\mathrm{s} / \mathrm{a}}=\sigma_{0}-R T \Gamma_{\max } \ln \left(1+\frac{V_{\mathrm{s}, i=\mathrm{stt}}^{\mathrm{b}}}{\alpha_{\mathrm{stt}} \beta V}\right)$

If no surfactants are present, all $\xi_{i}=1, \Gamma_{\max }=0, \sigma_{\mathrm{s} / \mathrm{a}}$ equals the value of pure water, and Eq. (7) is identical to that reported in Petters and Kreidenweis (2007). Since $\xi_{\text {sft }}<1$ generally holds for surfactants (i.e. the bulk is depleted), the contribution to the Raoult term, i.e. the net $\kappa$ of the mixture, is reduced together with the surface tension. Equations (5) and (7) describe the Köhler curve that is predicted for multicomponent particles that include one surfactant. The set of equations is easy to solve since all quantities entering the equation are clearly defined and can be determined from bulk measurements.

\subsection{Model assumptions}

The model presented here is a hybrid of the models reported in Petters and Kreidenweis (2007) and Raatikainen and Laaksonen (2011). A number of assumptions were made in the development of these equations and we explicitly state them here. Equation (3) assumes that the volume of solute plus water equals the total volume which allows using the pure water density to compute the partial molar volume of water in the Kelvin term (volume additivity assumption). Equation (4) assumes that sum of the water contents for the individual components at water activity $a_{\mathrm{w}}$ equals to the total water content in the mixture (Zdanovskii, Robinson and Stokes or ZSR assumption). The use of a single parameter for each component implies that the activity coefficient does not vary with the aerosol water content. In the derivation of Eq. (5) it was assumed that there are no common counter ions. For example, in a mixture of $\mathrm{NaCl}$ (solute 1) and sodium-dodecyl sulfate (solute 2), sodium ions $\left(\mathrm{Na}^{+}\right)$are common to both solutes. In this case, Eq. (5) is not valid because the activity of $\mathrm{Na}^{+}$in the bulk solution is increased due to the common ion, thereby changing the chemical potential gradient that drives the separation between the bulk and surface phases. As formulated here, only one surfactant is allowed to partition between the bulk and the surface. Equation (5) implicitly assumes that the activity coefficient is independent of the water content and that bulk solution concentration is directly proportional to the number of moles of the surfactant in the droplet. Equation (6) also assumes that only the surfactant partitions, i.e. the other solutes do not affect the surface tension, and that the chemical potential is well-modeled using concentration (dilute solution approximation).
Table 1. Physicochemical properties of sodium-dodecyl sulfate.

\begin{tabular}{lll}
\hline Property & Value & Reference \\
\hline$\alpha$ & $2.4518 \times 10^{-4} \mathrm{~m}^{3} \mathrm{~mol}^{-1}$ & $\begin{array}{l}\text { based on the density reported } \\
\text { in Sorjamaa et al. (2004) }\end{array}$ \\
$v$ & 2 & $\begin{array}{l}\text { Sorjamaa et al. (2004) } \\
\Gamma_{\max }\end{array}$ \\
$\beta$ & $5.71 \times 10^{-6} \mathrm{~mol} \mathrm{~m}^{-2}$ & Prisle et al. (2010) \\
$\kappa_{\text {chem }}$ & $0.5 \times 10^{-1} \mathrm{~mol} \mathrm{~m}^{3}$ & Prisle et al. (2010) \\
$\sigma_{\mathrm{s} / \mathrm{a}}\left(c_{\mathrm{cmc}}\right)$ & $\sim 0.134$ & Ruehl et al. (2010) \\
\hline
\end{tabular}

\subsection{Model inputs and execution}

To compute $S(D)$ from Eq. (7) for a ternary system consisting of surfactant a non-partitioning solute and water, a number of inputs must be specified. The surfactant is characterized by the set of parameters $\left\{\alpha_{\mathrm{sft}}, v, \kappa_{\mathrm{sft}}, \Gamma_{\max }, \beta\right\}$, the nonpartitioning solute by $\left\{\kappa_{\text {solute }}\right\}$ and the dry volume fractions by $\left\{\varepsilon_{\text {sft }}, \varepsilon_{\text {solute }}\right\}$, where it is understood that $\varepsilon_{\text {sft }}+\varepsilon_{\text {solute }}=1$. For a surfactant with known chemical identity, the molar volume $\left(\alpha_{\mathrm{sft}}\right)$ and dissociable ions $(v)$ are generally available. The corresponding $\kappa_{\text {sft }}$ may either be obtained from water activity data or measurements of the surfactants hygroscopic growth factor at high relative humidity. If neither are available, $\kappa_{\mathrm{sft}}$ can be estimated from $\alpha_{\mathrm{sft}}$ and $v$ if the surfactant is sufficiently soluble in water (Petters et al., 2009a). The surfactant properties $\left\{\Gamma_{\max }, \beta\right\}$ can be obtained from measuring the surface tension depression in bulk solutions for different concentrations and adjusting $\Gamma_{\max }$ and $\beta$ in Eq. (6) such that the residuals between the model and the data are minimized (e.g. Rehfeld, 1967; Tuckermann, 2007; Prisle et al., 2010). Table 1 summarizes these properties for the surfactant sodium-dodecyl sulfate (SDS).

In practice, the model calculations are then performed as follows: (1) the properties, $\kappa_{\mathrm{sft}}, \kappa_{\text {solute }}, \varepsilon_{\mathrm{sft}}$ and the dry particle diameter $D_{\mathrm{d}}$ are specified, (2) a wet diameter is chosen arbitrarily, (3) the surface area $\left(A=\pi D^{2}\right)$, droplet $(V=$ $\left.\pi D^{3} / 6\right)$ and dry aerosol volumes $\left(V_{\mathrm{s}}^{\mathrm{t}}=\pi D_{\mathrm{d}}^{3} / 6\right)$ are computed, (4) the bulk volume of the surfactant $\left(V_{\mathrm{s}, i=\mathrm{sft}}^{\mathrm{b}}\right.$; Eq. 5) and fraction present in the bulk $\left(\xi_{i}=V_{\mathrm{s}, \mathrm{sft}}^{\mathrm{b}} /\left(\varepsilon_{\mathrm{sft}} V_{\mathrm{s}}^{\mathrm{t}}\right)\right)$ are calculated, (5) the surface tension of the solution is computed via Eq. (6); if the computed $\sigma_{\mathrm{s} / \mathrm{a}}$ is less than what is predicted for the critical micelle concentration, $\sigma_{\mathrm{s} / \mathrm{a}}=\sigma_{\mathrm{s} / \mathrm{a}}\left(c_{\mathrm{cmc}}\right)$ is specified, and (6) the saturation ratio over the droplet is computed via Eq. (7). The procedure is repeated by stepping through a geometrically gridded array of wet diameters and the maximum of $S(D)$ vs. $D$ corresponds to the critical saturation ratio for the selected dry diameter. 


\subsection{Accounting for common counter ions}

As discussed earlier, Eq. (5) is not valid for systems with common counter ions (e.g. $\mathrm{NaCl}$ and SDS). Raatikainen and Laaksonen (2011, Eq. 17) provide an analytical solution for this case also:

$$
\begin{aligned}
& k_{1}=\frac{n^{-}}{v_{-}}+\frac{n^{+}}{v_{+}} \\
& k_{2}=\frac{\nu_{+}}{\nu_{-}} n^{-}+\frac{\nu_{-}}{v_{+}} n^{+} \\
& a_{0}=k_{2} n_{\mathrm{s}, i=\mathrm{sft}}^{\mathrm{t}} \beta V \\
& a_{1}=k_{2} n_{\mathrm{s}, i=\mathrm{sft}}^{\mathrm{t}}+\left(v n_{\mathrm{s}, i=\mathrm{sft}}^{\mathrm{t}}-k_{2}\right) \beta V-k_{1} A \Gamma_{\max } \\
& a_{2}=v n_{\mathrm{s}, i=\mathrm{sft}}^{\mathrm{t}}-k_{2}-v \beta V-A \Gamma_{\max } \\
& a_{3}=-v \\
& a_{0}+a_{1} n_{\mathrm{s}, i=\mathrm{sft}}^{\mathrm{b}}+a_{2}\left(n_{\mathrm{s}, i=\mathrm{sft}}^{\mathrm{b}}\right)^{2}+a_{3}\left(n_{\mathrm{s}, i=\mathrm{sft}}^{\mathrm{b}}\right)^{3}=0
\end{aligned}
$$

where we have transcribed the original equation to adopt our notation conventions. In Eq. (8) $n^{+}$and $n^{-}$denote the numbers of moles of common cations and anions, respectively. For SDS the number of cations $\left(v_{+}=1\right)$ equals the number of anions $\left(v_{-}=1\right)$. For a mixture of $\mathrm{SDS} / \mathrm{NaCl}$, there is no common anion $\left(n^{-}=0\right)$ and $n^{+}=n_{\mathrm{s}, i=\mathrm{NaCl}}^{\mathrm{t}}$ (Raatikainen and Laaksonen, 2011). For practical calculations, step 4 (Sect. 2.3) is modified by solving Eq. (8) instead of Eq. (5). In practice this is achieved as follows: (1) the quantities $\left\{n^{+}\right.$, $\left.n^{-}, v_{+}, v_{-}\right\}$are determined based on the specifics of the system, (2) the mole quantities are computed from the volumes of the constituents and the respective molar volumes $\left(n_{\mathrm{s}, i}^{\mathrm{t}}=\varepsilon_{i} V_{\mathrm{s}}^{\mathrm{t}} / \alpha_{i}\right)$, (3) the coefficients $\left\{k_{1}, k_{2}, a_{0}, a_{1}, a_{2}, a_{3}\right\}$ are computed according to their definitions given in Eq. (8), (4) the cubic equation is solved using a cube root solver algorithm of the users choice, (5) all negative and complex solutions are discarded, (6) the volume of material in the bulk is computed via $V_{\mathrm{s}, i=\mathrm{sft}}^{\mathrm{b}}=\alpha_{\mathrm{sft}} n_{\mathrm{s}, i=\mathrm{sft}}^{\mathrm{b}}$, and (7) the algorithm is completed following steps 5 and 6 described in Sect. 2.3.

\section{Discussion}

\subsection{Results from calculations}

We now show that Eqs. (5-8) reproduce results that are computed from standard partitioning theory (Li et al., 1998; Sorjamaa et al., 2004; Prisle et al., 2010; Raatikainen and Laaksonen, 2011). To demonstrate this we use the sodium dodecyl sulfate (SDS)/NaCl system that has been focused on by many of the previous investigators. Figure 1 shows the predicted critical supersaturation for a dry $40 \mathrm{~nm}$ SDS particle that is internally mixed with varying volume fractions of $\mathrm{NaCl}$. In our calculations we assumed $T=298.15 \mathrm{~K}, \sigma_{0}=$ $0.072 \mathrm{~J} \mathrm{~m}^{-2}, \kappa_{\mathrm{NaCl}}=1.28$ (Petters and Kreidenweis, 2007) and the relevant properties for SDS summarized in Table 1. These values differ slightly from those in previous studies (e.g., Sorjamaa et al. (2004) and Raatikainen and Laaksonen (2011) assumed $\kappa_{\mathrm{NaCl}}=1.35$ and $\kappa_{\mathrm{SDS}}=0.11, T=293 \mathrm{~K}$, $\sigma_{0}=0.073 \mathrm{~J} \mathrm{~m}^{-2}$ ). Calculation of the bulk concentration of the surfactant was performed using either Eqs. (5) or (8). As expected, the two models give identical results at $\varepsilon_{\mathrm{SDS}}=1$ since no $\mathrm{NaCl}$ is present. A strong increase in critical supersaturation is predicted when accounting for the common ion effect at $0.9<\varepsilon_{\mathrm{SDS}}<1$, which is also seen in the calculations presented by Prisle et al. (2010) and Raatikainen and Laaksonen (2011). The magnitude of the deviation between the treatments with and without common counter ion depends on the choice of dry diameter; for $40 \mathrm{~nm}$ particles this change should be easily observable with current stateof-the science $\mathrm{CCN}$ instrumentation. We therefore suggest that experiments specifically test this aspect of the theory by contrasting observations of internally mixed SDS/ $/ \mathrm{NaCl}$ and $\mathrm{SDS} / \mathrm{KCl}$ particles or similar systems. The rationale for this choice is that $\mathrm{KCl}$ has $\kappa$ that is similar to $\mathrm{NaCl}$ (Carrico et al., 2010) but $\mathrm{K}^{+}$would not provide a common counter ion.

\subsection{Mixing rules}

In Fig. 2 we converted the predicted critical supersaturation to $\kappa_{\text {app }}$ by converting calculated $S_{\mathrm{c}}, D_{\mathrm{d}}$ pairs shown in Fig. 1 to $\kappa$ using Eq. (1). For pure SDS particles, the predicted $\kappa_{\text {app }, \mathrm{SDS}}=0.18$, which is $34 \%$ larger than the observed $\kappa_{\text {chem }}$ at $99 \% \mathrm{RH}$, (Ruehl et al., 2010, $\kappa_{\text {chem,SDS }}=$ 0.134). For comparison the CCN measurements of Rood and Williams (2001) and Sorjamaa et al. (2004) can be described by $\kappa_{\text {app }, \text { SDS }}=0.18 \pm 0.018$ and $\kappa_{\text {app,SDS }}=0.15 \pm 0.014$, respectively, in apparent agreement with the calculations.

From a theoretical perspective the basic ZSR mixing rule reported in Petters and Kreidenweis (2007) is $\kappa=$ $\sum \varepsilon_{i} \kappa_{\mathrm{chem}, i}$ and is derived from Eq. (4). In practice, however, many investigators have applied $\kappa=\sum \varepsilon_{i} \kappa_{\mathrm{app}, i}$ successfully to ambient CCN measurements (Gunthe et al., 2009; Shinozuka et al., 2009; Dusek et al., 2010; Cerully et al., 2011). The results in Fig. 2 show that the mixing rule $\kappa=\sum \varepsilon_{i} \kappa_{\mathrm{app}, i}$ approximately holds for cases where the volume fraction of the surfactant is less than 0.5 , which is likely the case in ambient aerosol. We had conjectured that this approximation would be valid, based on mixtures containing the surface active compound fulvic acid (Petters and Kreidenweis, 2007) and the calculations presented here provide some theoretical basis for applying the mixing rule in cases where surface tension lowering plays a role. The validity of the mixing rule, however, is less obvious when the surfactant volume fraction exceeds $\sim 0.5$ and common ions are present.

There is a moderate dependence of $\kappa_{\text {app }}$ on the particle dry diameter indicated by the shaded areas in Fig. 2. This dependence is most pronounced at large surfactant volume fraction. Currently available data are too scattered to resolve these differences. So far only two studies have investigated the $\mathrm{CCN}$ activity of internally mixed $\mathrm{SDS} / \mathrm{NaCl}$ particles (Rood and Williams, 2001; Prisle et al., 2010). Although the 


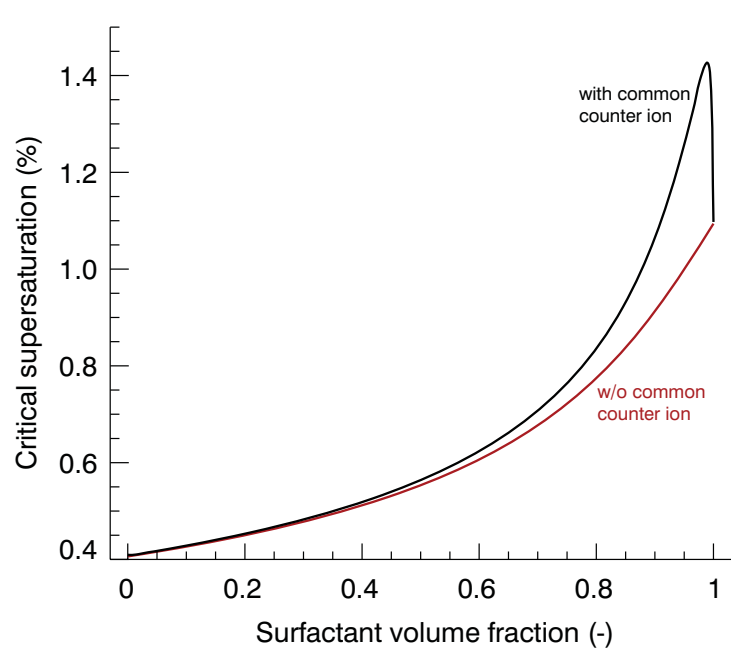

Fig. 1. Dependence of the critical supersaturation on SDS volume fraction for the $\mathrm{NaCl} / \mathrm{SDS}$ system using partitioning theory without common counter ion for $D_{\mathrm{d}}=40 \mathrm{~nm}$ (Eq. 5, red line) and partitioning theory accounting for the common counter ion for $D_{\mathrm{d}}=40 \mathrm{~nm}$ (Eq. 8, black line).

data are broadly consistent with partitioning theory, i.e. they show convincingly that the surface tension lowering is not expressed to the extent that would be expected from applying the lowered surface tension assuming no partitioning ${ }^{1}$, the data are too limited and too divergent to provide unequivocal evidence that Eq. (8) is a sufficiently accurate model of the process, particularly when also factoring in the similar results found for the sodium fatty acid salts mixtures studied by Prisle et al. (2010) (data not shown here). We believe that more data for the SDS/ $\mathrm{NaCl}$ and similar systems will be helpful to guide theory, analogous to the investigation of the $\mathrm{CCN}$ activity of the sparingly soluble adipic acid which has been studied by at least eight independent research groups (see Hings et al., 2008 and references therein).

\subsection{Model ambiguities}

Although a seemingly large number of approximations are present in the formulation of the partitioning problem that is presented here, there are several advantages to our simplified approach. Specifically, the solution is straightforward to implement in practice, computationally fast, and conceptually simple. The latter allows us to highlight ambiguities inherent in the current modeling framework and to discuss the need for future studies.

\footnotetext{
${ }^{1}$ If no bulk/surface partitioning is assumed, surface tension is computed via Eq. (6), applied to the Köhler equation with $\kappa_{\text {chem, SDS }}=0.134$, and the resulting $S_{\mathrm{c}}, D_{\mathrm{d}}$ pair parsed through Eq. (1) assuming the surface tension of pure water, $\kappa_{\text {app, }}$ SDS $=0.84$ and 1.82 would be expected for dry 100 and $40 \mathrm{~nm}$ pure SDS particles.
}

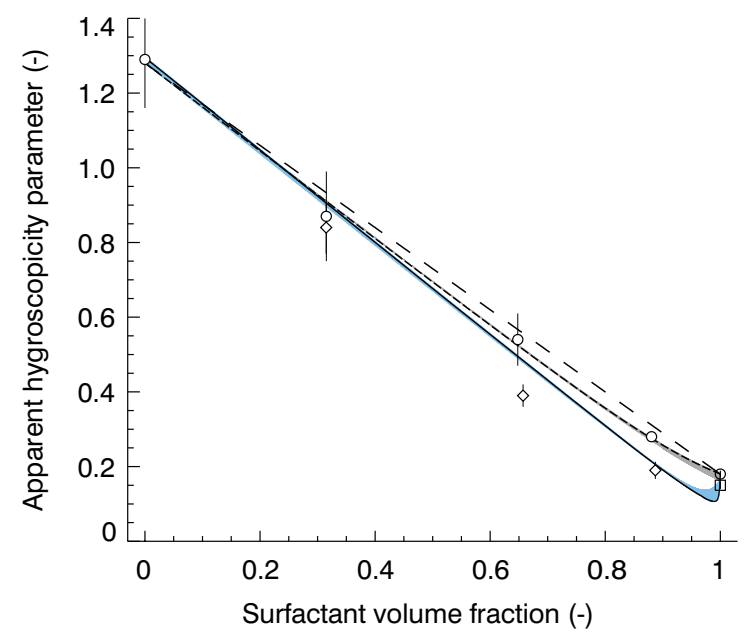

Fig. 2. Apparent hygroscopicity parameter vs. surfactant volume fraction the SDS/ $\mathrm{NaCl}$ system. Data are taken from Rood and Williams $(\bigcirc, 2001)$, Sorjamaa et al., ( $\square$, 2004), and Prisle et al., $(\diamond, 2010)$. Kappa was computed from Eq. (1) for each combination of supersaturation and dry diameter reported in the original manuscript. Horizontal bars correspond to \pm one standard deviation of the retrieved $\kappa_{\text {app }}$ values. The lines show model calculations using the linear mixing rule with apparent kappa as inputs (long dashed line), partitioning theory without common counter ion for $D_{\mathrm{d}}=40 \mathrm{~nm}$ (Eq. 5, short dashed line), and partitioning theory accounting for the common counter ion for $D_{\mathrm{d}}=40 \mathrm{~nm}$ (Eq. 8, solid line). The blue and grey shaded region shows the effect of varying the dry diameter between $40 \mathrm{~nm}<D_{\mathrm{d}}<200 \mathrm{~nm}$ in the calculations for partitioning theory.

An arbitrary surfactant is described by the parameter set $\left\{\alpha, v, \kappa_{\mathrm{chem}}, \Gamma_{\max }, \beta\right\}$ and values must obtained by measuring the molecular formula, density, and water activity and surface tension as function of surfactant concentration. In particular, reliable data for $\kappa_{\mathrm{chem}}, \Gamma_{\max }$, and $\beta$ are only available for a few systems. Measurements of the hygroscopic growth factor at RH > $98 \%$ (Hennig et al., 2005; Wex et al., 2009; Ruehl et al., 2010) can help constrain $\kappa_{\text {chem }}$ for not yet fully characterized surfactants. In general, $\Gamma_{\max }$ and $\beta$ are relatively easily obtained if a sufficient amount of material is available to do bulk experiments. Their values are catalogued for a number of atmospherically relevant compounds (Tuckermann, 2007) and can often be found in the literature for commercially available surfactants. Complications arise because $\beta$, and to a lesser extent $\Gamma_{\max }$, may depend on the other dry constituents (Rehfeld, 1967; Li et al., 1998; Prisle et al., 2010; Henning et al., 2005). This dependence can be accounted for by allowing $\beta$ to vary with the concentration of the other components in solution, but this type of treatment will remain intractable for all but a few well-characterized ternary systems. Studies that experimentally probe the parameter space are needed to gain further confidence in the theory.

The issue is further complicated when performing calculations on the bulk-to-surface partitioning of all compounds. 
A complete thermodynamic description should include calculations of surface excess for each species in solution. For the SDS/ $\mathrm{NaCl}$ system this includes $\mathrm{Na}^{+}, \mathrm{Cl}^{-}, \mathrm{C}_{12} \mathrm{H}_{25} \mathrm{SO}_{4}^{-}$, $\mathrm{H}_{2} \mathrm{O}, \mathrm{H}^{+}$and $\mathrm{OH}^{-}$(Pethica, 1954). In the simplified model presented here the implicit assumption is that $\Gamma_{C l-}=0$ (for the $\mathrm{NaCl} / \mathrm{SDS}$ system), which was confirmed experimentally by Tajima (1971) but the generality of this finding remains unclear. These problems are related to our larger understanding of the thermodynamic behavior of surfactant molecules in multicomponent solutions. While it might be possible to numerically solve the necessary equations for selected systems, and to verify the findings experimentally using bulk measurements, it is unlikely that the radial distribution of multiple and often unknown components in ambient particles can be understood at that level of detail within the foreseeable future.

An interesting, and perhaps provocative question is whether bulk-to-surface partitioning occurs at the timescale of $\mathrm{CCN}$ experiments. Observations show that surface tension gradually decreases with time until equilibrium is reached. The timescale for SDS depends on its concentration, but equilibration timescales for bulk solutions are generally $<0.3$ s (Kloubek, 1972). This slow equilibration time appears to be consistent with a model that includes kinetics of diffusion to the surface together with the adsorption/desorption on the surface (Chang and Franses, 1995). The timescale can be longer for certain surfactants and is not well understood when stable micelles limit the monomer flux (Patist et al., 2001). However, equilibration timescales may be shorter for microscopic droplets having thin surface layers relative to those found in bulk solutions.

During typical CCN experiments an initially dry particle is exposed to maximum supersaturation at timescales ranging from $\sim 1-5 \mathrm{~s}$ (Snider et al., 2010). If there are no kinetic limitations to hygroscopic growth and micelle disintegration, and kinetics are not affected by particle curvature, pure SDS particles should have sufficient time to express their equilibrium surface tension in $\mathrm{CCN}$ experiments. Kinetic limitations to hygroscopic growth, however, are observed for organic compounds (Sjogren et al., 2007). Further, water contents in SDS droplets at subsaturated relative humidity are well below the critical micelle concentration. Kinetic limitations of micelle dissolution, combined with kinetic limitations of water uptake may lead to non-equilibrium surface tension at the time of $\mathrm{CCN}$ activation in laboratory experiments. One indication that kinetic limitation may exist is the absence of evidence of the non-linear mixing in the presence of counter ions. For example, Prisle et al. (2010) present data for three sodium fatty acid salts mixed with $\mathrm{NaCl}$. The predicted increase in the critical supersaturation at high surfactant volume fraction is not evident in their data, hinting that the surface phase might not have fully formed. The implication is that in the laboratory, surfactants do not alter the surface tension and simply behave like other organic molecules that are not surface active. Whether this is indeed the case, and whether this conclusion would also be valid at the much longer timescales available in actual clouds, will require further detailed investigation.

The equations presented here can used to perform simulations to determine the degree of complexity that must be included in (global) model simulations. For example, Prisle et al. (2012) demonstrate that the sensitivity of simulated cloud droplet number concentration to the presence of surfactants is small in the ECHAM5.5-HAM2 model if surfactant partitioning is included. Aside from model applications, our equations can be used as a starting point for processlevel diagnostic studies. For example, it is straightforward to evaluate the extent to which discrepancies between $\kappa_{\text {chem }}$ and $\kappa_{\text {app }}$ can be attributed to surfactant properties. Absence of closure within this simplified framework should trigger indepth scrutiny of the underlying assumptions, e.g. non-ideal behavior in all phases, the choice of the dividing surface, kinetic limitation, or the assumption of zero surface excess for the non-surface active species.

\section{Summary}

We introduced a new set of equations that extends the kappa framework to account for bulk-to-surface partitioning of surfactant molecules. The extension is based on the analytical approximation presented by Raatikainen and Laaksonen (2011) and leads to an additional term $(\xi)$ that describes the fraction in the bulk phase and that enters into the kappa mixing rule. Both $\xi$ and $\sigma_{\mathrm{s} / \mathrm{a}}$ can be computed from a simple algebraic equation if the bulk physicochemical properties of the surfactant are known. At minimum, the surfactant properties that must be specified are its molar volume $(\alpha)$, the number of dissociating ions $(v)$, the kappa value describing the water uptake properties near the point of activation $\left(\kappa_{\text {chem }}\right)$, the maximum surface excess $\left(\Gamma_{\max }\right)$ and the inverse activity coefficient $(\beta)$.Partitioning theory predicts a strong effect for ternary systems where common ions are present, e.g. the system of sodium dodecyl sulfate and sodium chloride. By examining the existing laboratory data we show that there seems to be neither enough evidence to prove nor to disprove this effect and we speculate that the timescales required to form the thermodynamically stable surface phase may not be available in current laboratory experiments. Additional studies with more precise measurement techniques are needed to further examine the role of surfactants in cloud droplet activation. 
Appendix A

\section{Notation}

\begin{tabular}{|c|c|}
\hline & $\begin{array}{l}\text { Symbols } \\
\text { modified A-parameter from Köhler theory }\end{array}$ \\
\hline $\begin{array}{l}8.69251 \times \\
10^{-6} \mathrm{~K} \mathrm{~m}^{3} \mathrm{~J}^{-1}\end{array}$ & \\
\hline$A$ & particle surface area $\left(\mathrm{m}^{2}\right)$ \\
\hline$a_{\mathrm{w}}$ & activity of water in solution $(-)$ \\
\hline$c$ & solution concentration $\left(\mathrm{mol} \mathrm{m}^{-3}\right)$ \\
\hline$c_{\mathrm{cmc}}$ & critical micelle concentration $\left(\mathrm{mol} \mathrm{m}^{-3}\right)$ \\
\hline$D$ & wet droplet diameter (m) \\
\hline$D_{\mathrm{d}}$ & dry particle diameter $(\mathrm{m})$ \\
\hline$M_{\mathrm{W}}$ & molecular weight of water $\left(\mathrm{kg} \mathrm{mol}^{-1}\right)$ \\
\hline$n$ & number of moles (mol) \\
\hline$R$ & universal gas constant $\left(\mathrm{J} \mathrm{K}^{-1} \mathrm{~mol}^{-1}\right)$ \\
\hline $\mathrm{RH}$ & relative humidity (\%) \\
\hline$S$ & saturation ratio $(-)$ \\
\hline$T$ & temperature $(\mathrm{K})$ \\
\hline V & volume $\left(\mathrm{m}^{3}\right)$ \\
\hline$\alpha$ & molar volume $\left(\mathrm{m}^{3} \mathrm{~mol}^{-1}\right)$ \\
\hline$\beta$ & inverse activity coefficient $\left(\mathrm{mol} \mathrm{m}^{-3}\right)$ \\
\hline$\varepsilon$ & $\begin{array}{l}\text { volume fraction of dry component in the } \\
\text { particle }(-)\end{array}$ \\
\hline$\xi$ & $\begin{array}{l}\text { fraction of solute volume present in the } \\
\text { bulk phase (-) }\end{array}$ \\
\hline$\Gamma_{\max }$ & maximum surface excess $\left(\mathrm{mol} \mathrm{m}^{-2}\right)$ \\
\hline 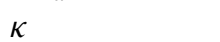 & hygroscopicity parameter $(-)$ \\
\hline$v=v_{+}+v_{-}$ & $\begin{array}{l}\text { number of cations }\left(v_{+}\right) \text {and anions }\left(v_{-}\right) \text {the } \\
\text { surfactant dissociates into }\end{array}$ \\
\hline $\begin{array}{l}\rho_{\mathrm{w}}= \\
\mathrm{kg} \mathrm{m}^{3}\end{array}$ & density of water $\left(\mathrm{kg} \mathrm{m}^{3}\right)$ \\
\hline $\begin{array}{l}\sigma_{0}= \\
0.072 \mathrm{~J} \mathrm{~m}^{-2}\end{array}$ & $\begin{array}{l}\text { surface tension at zero surfactant concen- } \\
\text { tration }\left(\mathrm{J} \mathrm{m}^{-2}\right)\end{array}$ \\
\hline$\sigma_{\mathrm{s} / \mathrm{a}}$ & $\begin{array}{l}\text { surface tension of the solution/air interface } \\
\left(\mathrm{J} \mathrm{m}^{-2}\right)\end{array}$ \\
\hline
\end{tabular}

$i=1,2,3 \ldots$

$\mathrm{s}$

sft

w

SDS

$\mathrm{NaCl}$

$\mathrm{c}$

$\mathrm{b}$
$\mathrm{s}$
$\mathrm{t}$

\section{Subscripts}

component number

solute

surfactant

water

sodium dodecyl sulfate $\left(\mathrm{NaC}_{12} \mathrm{H}_{25} \mathrm{SO}_{4}\right)$

sodium chloride $(\mathrm{NaCl})$

critical

\section{Superscripts}

bulk phase

surface phase

total solution phase (bulk plus surface)
Acknowledgements. This work was funded by the Office of Science (BER), US Department of Energy under grant DE-SC0006633.

Edited by: G. McFiggans

\section{References}

Bianco, H. and Marmur, A.: The Dependence of the surface tension of surfactant solutions on drop size, J. Coll. Interf. Sci., 151, 517522, 1992.

Carrico, C. M., Petters, M. D., Kreidenweis, S. M., Collett, J. L., Engling, G., and Malm, W. C.: Aerosol hygroscopicity and cloud droplet activation of extracts of ?lters from biomass burning experiments, J. Geophys. Res., 113, 08206, doi:10.1029/2007JD009274, 2008.

Carrico, C. M., Petters, M. D., Kreidenweis, S. M., Sullivan, A. P., McMeeking, G. R., Levin, E. J. T., Engling, G., Malm, W. C., and Collett Jr., J. L.: Water uptake and chemical composition of fresh aerosols generated in open burning of biomass, Atmos. Chem. Phys., 10, 5165-5178, doi:10.5194/acp-10-5165-2010, 2010.

Cerully, K. M., Raatikainen, T., Lance, S., Tkacik, D., Tiitta, P., Petäjä, T., Ehn, M., Kulmala, M., Worsnop, D. R., Laaksonen, A., Smith, J. N., and Nenes, A.: Aerosol hygroscopicity and CCN activation kinetics in a boreal forest environment during the 2007 EUCAARI campaign, Atmos. Chem. Phys., 11, 12369-12386, doi:10.5194/acp-11-12369-2011, 2011.

Chan, M. N., Kreidenweis, S. M., and Chan, C. K.: Measurements of the Hygroscopic and Deliquescence Properties of Organic Compounds of Different Solubilities in Water and Their Relationship with Cloud Condensation Nuclei Activities, Environ. Sci. Technol., 42, 3602-3608, 2008.

Chang, C.-H. and Franses, E. I.: Adsorption dynamics of surfactants at the air/water interface: a critical review of mathematical models, data, and mechanisms, Colloid and Surfaces A: Physicochem. Eng. Aspects, 100, 1-45, 1995.

Christensen, S. I. and Petters, M. D.: The role of temperature in cloud droplet activation, J. Phys. Chem. A, 116, 9706-9717, doi:10.1021/jp3064454, 2012.

Clegg, S. L., Brimblecombe, P., and Wexler, A. S.:Thermodynamic model of the system $\mathrm{H}^{+}-\mathrm{NH}_{4}^{+}-\mathrm{Na}^{+}-\mathrm{SO}_{4}^{2-}-\mathrm{NO}_{3}^{-}-\mathrm{Cl}^{-}$$\mathrm{H}_{2} \mathrm{O}$ at $298.15 \mathrm{~K}$, J. Phys. Chem. A, 102, 2155-2171, doi:10.1021/jp973043j, 1998.

Duplissy, J., Gysel, M., Alfarra, M. R., Dommen, J., Metzger, A., Prevot, A. S. H., Weingartner, E., Laaksonen, A., Raatikainen, T., Good, N., Turner, S. F., McFiggans, G., and Baltensperger, U.: Cloud forming potential of secondary organic aerosol under near atmospheric conditions, Geophys. Res. Lett., 35, L03818, doi:03810.01029/02007GL031075, 2008.

Dusek, U., Frank, G. P., Curtius, J., Drewnick, F., Schneider, J., Kürten, A., Rose, D., Andreae, M. O., Borrmann, S., and Pöschl, U.: Enhanced organic mass fraction and decreased hygroscopicity of cloud condensation nuclei $(\mathrm{CCN})$ during new particle formation events, Geophys. Res. Lett., 37, L03804, doi:10.1029/2009GL040930, 2010.

Engelhart, G. J., Asa-Awuku, A., Nenes, A., and Pandis, S. N.: CCN activity and droplet growth kinetics of fresh and aged monoterpene secondary organic aerosol, Atmos. Chem. Phys., 8, 39373949, doi:10.5194/acp-8-3937-2008, 2008. 
Facchini, M. C., Mircea, M., Fuzzi, S., and Charlson, R. J.: Cloud albedo enhancement by surface-active organic solutes in growing droplets, Nature, 401, 257-259, doi:10.1038/45758, 1999.

Facchini, M. C., Descesari, S., Mircea, M., Fuzzi, S., and Loglio, G.: Surface tension of atmospheric wet aerosol and cloud/fog droplets in relation to their organic carbon content and chemical composition, Atmos. Environ., 34, 4853-4857, 2000.

George, I. J. and Abbatt, J. P. D.: Chemical evolution of secondary organic aerosol from $\mathrm{OH}$-initiated heterogeneous oxidation, Atmos. Chem. Phys., 10, 5551-5563, doi:10.5194/acp-10-55512010, 2010

Good, N., Topping, D. O., Allan, J. D., Flynn, M., Fuentes, E., Irwin, M., Williams, P. I., Coe, H., and McFiggans, G.: Consistency between parameterisations of aerosol hygroscopicity and CCN activity during the RHaMBLe discovery cruise, Atmos. Chem. Phys., 10, 3189-3203, doi:10.5194/acp-10-3189-2010, 2010a.

Good, N., Topping, D. O., Duplissy, J., Gysel, M., Meyer, N. K., Metzger, A., Turner, S. F., Baltensperger, U., Ristovski, Z., Weingartner, E., Coe, H., and McFiggans, G.: Widening the gap between measurement and modelling of secondary organic aerosol properties?, Atmos. Chem. Phys., 10, 2577-2593, doi:10.5194/acp-10-2577-2010, 2010b.

Gunthe, S. S., King, S. M., Rose, D., Chen, Q., Roldin, P., Farmer, D. K., Jimenez, J. L., Artaxo, P., Andreae, M. O., Martin, S. T., and Pöschl, U.: Cloud condensation nuclei in pristine tropical rainforest air of Amazonia: size-resolved measurements and modeling of atmospheric aerosol composition and CCN activity, Atmos. Chem. Phys., 9, 7551-7575, doi:10.5194/acp-9-75512009, 2009.

Henning, S., Rosenørn, T., D’ Anna, B., Gola, A. A., Svenningsson, B., and Bilde, M.: Cloud droplet activation and surface tension of mixtures of slightly soluble organics and inorganic salt, Atmos. Chem. Phys., 5, 575-582, doi:10.5194/acp-5-575-2005, 2005.

Hings, S. S., Wrobel, W. C., Cross, E. S., Worsnop, D. R., Davidovits, P., and Onasch, T. B.: CCN activation experiments with adipic acid: effect of particle phase and adipic acid coatings on soluble and insoluble particles, Atmos. Chem. Phys., 8, 37353748, doi:10.5194/acp-8-3735-2008, 2008.

Irwin, M., Good, N., Crosier, J., Choularton, T. W., and McFiggans, G.: Reconciliation of measurements of hygroscopic growth and critical supersaturation of aerosol particles in central Germany, Atmos. Chem. Phys., 10, 11737-11752, doi:10.5194/acp10-11737-2010, 2010.

Jimenez, J. L., Canagaratna, M. R., Donahue, N. M., Prevot, A. S., Zhang, Q., Kroll, J. H., DeCarlo, P. F., Allan, J.D., Coe, H., Ng, N. L., Aiken, A. C., Docherty, K. S., Ulbrich, I. M., Grieshop, A. P., Robinson, A. L., Duplissy, J., Smith, J. D., Wilson, K. R., Lanz, V. A., Hueglin, C., Sun, Y. L., Tian, J., Laaksonen, A., Raatikainen, T., Rautiainen, J., Vaattovaara, P., Ehn, M., Kulmala, M., Tomlinson, J. M., Collins, D. R., Cubison, M. J., Dunlea, E. J., Huffman, J. A., Onasch, T. B., Alfarra, M. R., Williams, P. I., Bower, K., Kondo, Y., Schneider, J., Drewnick, F., Borrmann, S., Weimer, S., Demerjian, K., Salcedo, D., Cottrell, L., Griffin, R., Takami, A., Miyoshi, T., Hatakeyama, S., Shimono, A., Sun, J. Y., Zhang, Y. M., Dzepina. K., Kimmel, J. R., Sueper, D., Jayne, J. T., Herndon, S. C., Trimborn, A. M., Williams, L. R., Wood, E. C., Middlebrook, A. M., Kolb, C. E., Baltensperger, U., and Worsnop, D. R.: Evolution of organic aerosols in the at- mosphere, Science, 326, 1525-1529, 2009.

King, S. M., Rosenoern, T., Shilling, J. E., Chen, Q., and Martin, S. T.: Increased cloud activation potential of secondary organic aerosol for atmospheric mass loadings, Atmos. Chem. Phys., 9, 2959-2971, doi:10.5194/acp-9-2959-2009, 2009.

Kloubek, J.: Measurement of the dynamic surface tension by the maximum bubble pressure method. IV. Surface tension of aqueous solutions of sodium dodecyl sulfate, J. Colloid Interface. Sci., 41, 17-22, 1972.

Kreidenweis, S. M., Koehler, K., DeMott, P. J., Prenni, A. J., Carrico, C., and Ervens, B.: Water activity and activation diameters from hygroscopicity data - Part I: Theory and application to inorganic salts, Atmos. Chem. Phys., 5, 1357-1370, doi:10.5194/acp-5-1357-2005, 2005.

Kreidenweis, S. M., Petters, M. D., and Chuang, P. Y.: Cloud particle precursors, Clouds in the Perturbed Climate System: Their Relationship to Energy Balance, Atmospheric Dynamics, and Precipitation, Strüngmann Forum Report, edited by: Heintzenberg, J. and Charlson, R. J., The MIT Press, 13, Cambridge, Massachusetts, ISBN 978-0-262-01287-4, 2009.

Li, Z., Williams, A. L., and Rood, M. J.: In?uence of soluble surfactant properties on the activation of aerosol particles containing inorganic solute, J. Atmos. Sci., 55, 1859-1866, 1998

Lohmann, U. and Hoose, C.: Sensitivity studies of different aerosol indirect effects in mixed-phase clouds, Atmos. Chem. Phys., 9, 8917-8934, doi:10.5194/acp-9-8917-2009, 2009.

Mochida, M., Nishita-Hara, C., Kitamori, Y., Aggarwal, S. G., Kawamura, K., Miura, K., and Takami, A.: Size-segregated measurements of cloud condensation nucleus activity and hygroscopic growth for aerosols at Cape Hedo, Japan, in spring 2008, J. Geophys. Res., 115, 20 D21207, doi:10.1029/2009JD013216, 2010.

Moore, R. H, Ingall, E. D., Sorooshian, A., and Nenes, A.: Molar mass, surface tension, and droplet growth kinetics of marine organics from measurements of CCN activity, Geophys. Res. Lett., 35, L07801, doi:10.1029/2008GL033350, 2008.

Padro, L. T., Tkacik, D., Lathem, T., Hennigan, C., Sullivan, A. P., Weber, R. J., Huey, L. G., and Nenes, A.: Investigation of cloud condensation nuclei properties and droplet growth kinetics of the water-soluble aerosol fraction in Mexico City, J. Geophys. Res., 115, D09204, doi:10.1029/2009JD013195, 2010.

Patist, A., Oh. S. G., Leung, R., and Shah, D. O.:Kinetics of micellization: its significance to technological processes, Colloid and Surfaces A: Phyiscochem. Eng. Aspects, 176, 3-16, 2001.

Pethica, B. A.: The adsorption of surface active electrolytes at the air/water interface, Trans. Faraday Soc., 50, 413-421, doi:10.1039/TF9545000413, 1954

Petters, M. D. and Kreidenweis, S. M.: A single parameter representation of hygroscopic growth and cloud condensation nucleus activity, Atmos. Chem. Phys., 7, 1961-1971, doi:10.5194/acp-71961-2007, 2007.

Petters, M. D. and Kreidenweis, S. M.: A single parameter representation of hygroscopic growth and cloud condensation nucleus activity - Part 2: Including solubility, Atmos. Chem. Phys., 8, 6273-6279, doi:10.5194/acp-8-6273-2008, 2008.

Petters, M. D., Kreidenweis, S. M., Prenni, A. J., Sullivan, R. C., Carrico, C. M., Koehler, K. A., and Ziemann, P. J.: Role of molecular size in cloud droplet activation, Geophys. Res Lett., 36, L22801, doi:10.1029/2009GL040131, 2009a. 
Petters, M. D., Wex, H., Carrico, C. M., Hallbauer, E., Massling, A., McMeeking, G. R., Poulain, L., Wu, Z., Kreidenweis, S. M., and Stratmann, F.: Towards closing the gap between hygroscopic growth and activation for secondary organic aerosol - Part 2: Theoretical approaches, Atmos. Chem. Phys., 9, 3999-4009, doi:10.5194/acp-9-3999-2009, 2009b.

Petters, M. D., C. M. Carrico, S. M. Kreidenweis, A. J. Prenni, P. J. DeMott, J. R. Collett Jr., and H. Moosmüller, Cloud condensation nucleation ability of biomass burning aerosol, J Geophys. Res., 114, D22205, doi:10.1029/2009JD012353, 2009c.

Pöschl, U., Rose, D., and Andreae, M. O.: Strüngmann Forum Report, Clouds in the perturbed climate system: Their relationship to energy balance, atmospheric dynamics, and precipitation. Particle hygroscopicity and cloud condensation nuclei activity, MIT Press, Cambridge, Massachusetts, ISBN 978-0-262-012874, 2009.

Prenni, A. J., Petters, M. D., DeMott, P. J., Kreidenweis, S. M., Ziemann, P. J., Matsunaga, A., and Lim, Y. B.: Cloud drop activation of secondary organic aerosol, J. Geophys. Res., 112, D10223, doi:10210.11029/12006JD007963, 2007.

Prisle, N. L., Raatikainen, T., Sorjamaa, R., Svenningsson, B., Laaksonen, A., and Bilde, M.: Surfactant partitioning in cloud droplet activation: a study of $\mathrm{C} 8, \mathrm{C} 10, \mathrm{C} 12$ and $\mathrm{C} 14$ normal fatty acid sodium salts, Tellus, 60B, 416-431, doi:10.1111/j.16000889.2008.00352.x, 2008.

Prisle, N. L., Raatikainen, T., Laaksonen, A., and Bilde, M.: Surfactants in cloud droplet activation: mixed organic-inorganic particles, Atmos. Chem. Phys., 10, 5663-5683, doi:10.5194/acp-105663-2010, 2010.

Prisle, N. L., Dal Maso, M., and Kokkola, H.: A simple representation of surface active organic aerosol in cloud droplet formation, Atmos. Chem. Phys., 11, 4073-4083, doi:10.5194/acp-11-40732011, 2011.

Prisle, N. L., Asmi, A., Topping, D., Partanen, A.-I., Romakkaniemi, S., Dal Maso, M., Kulmala, M., Laaksonen, A. , Lehtinen, K. E. J., McFiggans, G., and Kokkola, H.: Surfactant effects in global simulations of cloud droplet activation, Geophys. Res. Lett., 39, L05802, doi:10.1029/2011GL050467, 2012.

Raatikainen, T. and Laaksonen, A.: A simplified treatment of surfactant effects on cloud drop activation, Geosci. Model Dev., 4, 107-116, doi:10.5194/gmd-4-107-2011, 2011.

Rehfeld, S. J.: Adsorption of sodium dodecyl sulfate at various hydrocarbon-water interfaces, J. Phys. Chem., 71, 738-745, 1967.

Rissler, J., Vestin, A., Swietlicki, E., Fisch, G., Zhou, J., Artaxo, P., and Andreae, M. O.: Size distribution and hygroscopic properties of aerosol particles from dry-season biomass burning in Amazonia, Atmos. Chem. Phys., 6, 471-491, doi:10.5194/acp6-471-2006, 2006.

Rissler, J., Svenningsson, B., Fors, E. O., Bilde, M., and Swietlicki, E.: An evaluation and comparison of cloud condensation nucleus activity models: Predicting particle critical saturation from growth at subsaturation, J. Geophys. Res., 115, D22208, doi:10.1029/2010JD014391, 2010.

Rood, M. J. and Williams, A. L.: Reply, J. Atmos. Sci., 58, 14681473, 2001.

Ruehl, C. R., Chuang, P. Y., and Nenes, A.: Aerosol hygroscopicity at high (99 to $100 \%)$ relative humidities, Atmos. Chem. Phys., 10, 1329-1344, doi:10.5194/acp-10-1329-2010, 2010.
Seidl, W. and Hanel, G.: Surface-Active Substances on Rainwater and Atmospheric Particles, Pure Appl. Geophys., 121, 10771093, 1983.

Seinfeld, J. H. and Pandis, S. N.: Atmospheric Chemistry and Physics: From Air Pollution to Climate Change, John Wiley \& Sons, Hoboken, New Jersey, ISBN 978-0-471-72017-1, 2006.

Sjogren, S., Gysel, M., Weingartner, E., Baltensperger, U., Cubison, M. J., Coe, H., Zardini, A., Marcolli, C., Krieger, U. K., and Peter, T.: Hygroscopic growth and water uptake kinetics of two-phase aerosol particles consisting of ammonium sulfate, adipic and humic acid mixtures, J. Aerosol Sci., 38, 157-171, doi:10.1016/j.jaerosci.2006.11.005, 2007.

Snider, J. R., Wex, H., Rose, D., Kristensson, A., Stratmann, F., Hennig, T., Henning, S., Kiselev, A., Bilde, M., Burkhardt, M., Dusek, U., Frank, G. P., Kiendler-Scharr, A., Mentel, Th. F., Petters, M. D., and Pöschl, U.: Intercomparison of CCN and hygroscopic fraction measurements from LExNo, J. Geophys. Res., 115, D11205, doi:10.1029/2009JD012618, 2010.

Sorjamaa, R., Svenningsson, B., Raatikainen, T., Henning, S., Bilde, M., and Laaksonen, A.: The role of surfactants in Köhler theory reconsidered, Atmos. Chem. Phys., 4, 2107-2117, doi:10.5194/acp-4-2107-2004, 2004.

Shinozuka, Y., Clarke, A. D., DeCarlo, P. F., Jimenez, J. L., Dunlea, E. J., Roberts, G. C., Tomlinson, J. M., Collins, D. R., Howell, S. G., Kapustin, V. N., McNaughton, C. S., and Zhou, J.: Aerosol optical properties relevant to regional remote sensing of $\mathrm{CCN}$ activity and links to their organic mass fraction: airborne observations over Central Mexico and the US West Coast during MILAGRO/INTEX-B, Atmos. Chem. Phys., 9, 6727-6742, doi:10.5194/acp-9-6727-2009, 2009.

Shulman, M. L., Jacobson, M. C., Charlson, R. J., Synovec, R. E., and Young, T. E.: Dissolution behavior and surface tension effects of organic compounds in nucleating cloud droplets, Geophys. Res. Lett., 23, 277-280, 1996.

Sullivan, R. C., Moore, M. J. K., Petters, M. D., Kreidenweis, S. M., Roberts, G. C., and Prather, K. A.: Effect of chemical mixing state on the hygroscopicity and cloud nucleation properties of calcium mineral dust particles, Atmos. Chem. Phys., 9, 33033316, doi:10.5194/acp-9-3303-2009, 2009a.

Sullivan, R. C., Moore, M. J. K., Petters, M. D., Kreidenweis, S. M., Roberts, G. C., and Prather, K. A.: Timescale for hygroscopic conversion of calcite mineral particles through heterogeneous reaction with nitric acid, Phys. Chem. Chem. Phys., 11, 7826-7837, doi:10.1039/b904217b, 2009b.

Svenningsson, B., Hansson, H. C., Wiedensohler, A., Noone, K., Ogren, J., Hallberg, A., and Colvile, R.: Hygroscopic Growth of Aerosol-Particles and Its Influence on Nucleation Scavenging inCloud - Experimental Results from Kleiner-Feldberg, J. Atmos. Chem., 19, 129-152, 1994.

Tajima, K.: Radiotracer studies on adsorption of surface active substance at aqueous surface. III. The effects of salt on the adsorption of sodium dodecylsulfate, Bull. Chem. Soc. Jap., 44, 1767$1771,1971$.

Topping, D.: An analytical solution to calculate bulk mole fractions for any number of components in aerosol droplets after considering partitioning to a surface layer, Geosci. Model Dev., 3, 635642, doi:10.5194/gmd-3-635-2010, 2010.

Tuckermann, R.: Surface tension of aqueous solutions of watersoluble organic and inorganic compounds, Atmos. Environ., 41, 
6265-6275, 2007.

Tuckermann, R. and Cammenga, H. K.: The surface tension of aqueous solutions of some atmospheric water-soluble organic compounds, Atmos. Environ., 38, 6135-6138, 2004.

Vestin, A., Rissler, J., Swietlicki, E., Frank, G. P., and Andreae, M. O.: Cloud-nucleating properties of the Amazonian biomass burning aerosol: Cloud condensation nuclei measurements and modeling, J. Geophys. Res., 112, D14201, doi:10.1029/2006JD008104, 2007.

Wex, H., Hennig, T., Salma, I., Ocskay, R., Kiselev, A., Henning, S., Massling, A., Wiedensohler, A., and Stratmann, F.: Hygroscopic growth and measured and modeled critical super-saturations of an atmospheric HULIS sample, Geophys. Res. Lett., 34, L02818, doi:10.1029/2006GL028260, 2007.
Wex, H., Petters, M. D., Carrico, C. M., Hallbauer, E., Massling, A., McMeeking, G. R., Poulain, L., Wu, Z., Kreidenweis, S. M., and Stratmann, F.: Towards closing the gap between hygroscopic growth and activation for secondary organic aerosol: Part $1-$ Evidence from measurements, Atmos. Chem. Phys., 9, 3987-3997, doi:10.5194/acp-9-3987-2009, 2009.

Wex, H., Fuentes, E., Tsagkogeorgas, G., Voigtlnder, J., Clauss, T., Kiselev, A., Green, D., Coe, H., McFiggans, G., and Stratmann, F.: The in?uence of algal exudate on the hygroscopicity of sea spray particles, Advances in Meteorology, 2010, 365131, doi:10.1155/2010/365131, 2010. 